\title{
Influence of excessive weight loss after gastroplasty for morbid obesity on respiratory muscle performance
}

Paltiel Weiner, Joseph Waizman, Margalit Weiner, Marinella Rabner, Rasmi Magadle, Doron Zamir

\begin{abstract}
Background - Morbidly obese subjects are known to have impaired respiratory function and inefficient respiratory muscles. A study was undertaken to investigate the influence of excessive weight loss on pulmonary and respiratory muscle function in morbidly obese individuals who underwent gastroplasty to induce weight loss. Methods - Twenty one obese individuals with mean (SE) body mass index (BMI) $41.5(4.5) \mathrm{kg} / \mathrm{m}^{2}$ without overt obstructive airways disease $\left(\mathrm{FEV}_{1} / \mathrm{FVC}\right.$ ratio $\left.>80 \%\right)$ were studied before and six months after vertical banded gastroplasty. Only patients who had lost at least $20 \%$ of baseline BMI were included in the study. Standard pulmonary function tests and respiratory muscle strength and endurance were measured.
\end{abstract}

Results - Before operation the predominant abnormalities in respiratory function were significant reductions in lung volumes and respiratory muscle endurance and, to a lesser degree, reductions in respiratory muscle strength. All parameters increased towards normal values after weight loss with significant increases in functional residual capacity (FRC) from 84.0 (2.2) to $91.3(2.5) \%$ of predicted normal values (mean difference $7.3,95 \%$ confidence interval of difference (CI) 4.2 to 10.5), total lung capacity (TLC) from 85.6 (3.0) to $93.5(3.7) \%$ of predicted normal values (mean difference $7.9,95 \%$ CI 4.5 to $11.5)$, residual volume (RV) from 86.7 (3.1) to $96.4(3.0) \%$ of predicted normal values (mean difference $9.7,95 \%$ CI 5.2 to 14.1 ), expiratory reserve volume (ERV) from 76.6 (3.0) to $89.0(3.4) \%$ of predicted normal values (mean difference $12.4,95 \% \mathrm{CI}$ 6.3 to 18.9$)$, respiratory muscle strength: PImax from 92 (4.4) to $113(4.6) \mathrm{cm} \mathrm{H}_{2} \mathrm{O}$ (mean difference $21,95 \%$ CI 12.2 to 31.6 ), Pemax from 144 (5.6) to $166(4.3) \mathrm{cm} \mathrm{H}_{2} \mathrm{O}$ (mean difference 22, 95\% CI 12.9 to 32.0 ), and endurance: PmPeak/PImax from 56 (1.4) to $69(2.0) \%$ (mean difference $13,95 \%$ CI 9.7 to 16.9). The strongest correlation was between weight loss and the improvement in respiratory muscle endurance.

Conclusions - Lung volumes and respiratory muscle performance are decreased in obese individuals. Weight loss following gastroplasty is associated with improvement in lung volumes and respiratory muscle function.

(Thorax 1998;53:39-42)

Keywords: respiratory muscle strength, respiratory muscle endurance, weight loss.

It is well established that obesity without associated disease affects respiratory function in humans, the most persistent abnormality being a restrictive respiratory impairment. ${ }^{1-4}$ The most characteristic pulmonary function abnormalities in obesity are reduced expiratory reserve volume (ERV) and functional residual capacity (FRC), due to alterations in chest wall mechanics. ${ }^{156}$ Other lung volumes, as well as the maximal voluntary ventilation (MVV) and flow rates, have been variously reported as normal, increased, or decreased. ${ }^{78}$ The respiratory muscles are inefficient in obese individuals ${ }^{9}$ and the MVV, which may be affected by reduced respiratory muscle strength, was also found to be low in obese patients. ${ }^{10}$

There are few studies that deal with the effect of weight loss on respiratory function. Increased vital capacity (VC), ERV, FRC, and total lung capacity (TLC) have all been described. ${ }^{1112}$ Respiratory muscle performance has been less frequently studied. Wadström and associates ${ }^{13}$ found a decrease in respiratory muscle strength following weight reduction of $10 \%$ after gastroplasty but several weeks later, when the mean weight loss was already $18 \%$, the respiratory muscle strength did not differ from baseline values.

We have studied pulmonary function and respiratory muscle performance in a group of obese individuals without evidence of significant airway obstruction, before and after weight loss following gastroplasty.

\section{Methods}

Twenty one otherwise healthy obese patients of mean (SE) age 41 (2.1) years (range 25-52) and mean body mass index (BMI) 41.5 (4.5) $\mathrm{kg} / \mathrm{m}^{2}$ were studied before and six months after banded gastroplasty performed to induce weight loss. BMI was calculated as body weight/ height ${ }^{2}$. Only patients with BMI $>33 \mathrm{~kg} / \mathrm{m}^{2}$ before surgery and who had lost at least $20 \%$ of their BMI six months after the operation were recruited for the study. Patients with an $\mathrm{FEV}_{1} / \mathrm{FVC}$ ratio of $<80 \%$ were excluded from 
Table 1 Mean (SE) spirometric parameters in obese subjects

\begin{tabular}{llll}
\hline & Before surgery & After surgery & Mean difference (95\% CI) \\
\hline FVC (\% pred) & $75.6(3.2)$ & $84.6(4.3)^{* *}$ & $9.0(6.4$ to 11.7$)$ \\
FEV $_{1}$ (\% pred) & $83.2(4.8)$ & $86.3(4.5)$ & $3.1(2.4$ to 3.8$)$ \\
FEV $_{1} /$ FVC (\%) & $81.6(4.8)$ & $83.0(3.8)$ & $1.4(0.9$ to 1.9$)$ \\
\hline
\end{tabular}

$\mathrm{FVC}=$ forced vital capacity; $\mathrm{FEV}_{1}=$ forced expiratory volume in one second.

** Statistically significant.

Table 2 Mean (SE) lung volumes in obese subjects

\begin{tabular}{lccc}
\hline & Before surgery & After surgery & Mean difference (95\% CI) \\
\hline TLC (\% pred) & $85.6(3.0)$ & $93.5(3.7)^{* *}$ & $7.9(4.5$ to 11.5$)$ \\
FRC (\% pred) & $84.0(2.2)$ & $91.3(2.5)^{* *}$ & $7.3(4.2$ to 10.5$)$ \\
RV (\% pred) & $86.7(3.1)$ & $96.4(3.0)^{* *}$ & $9.7(5.2$ to 14.1$)$ \\
ERV (\% pred) & $76.6(3.0)$ & $89.0(3.4)^{* *}$ & $12.4(6.3$ to 18.9$)$ \\
RV/TLC (\% pred) & $102.3(4.1)$ & $106.8(4.0)$ & $4.5(3.1$ to 6.0) \\
\hline
\end{tabular}

$\mathrm{TLC}=$ total lung capacity; $\mathrm{FRC}=$ functional residual capacity; $\mathrm{RV}=$ residual volume; $\mathrm{ERV}=$ expiratory reserve volume.

** Statistically significant.

the study. No patient was hypoxic before the operation.

\section{MEASUREMENTS}

Spirometric parameters

Forced vital capacity (FVC) and forced expiratory volume in one second $\left(\mathrm{FEV}_{1}\right)$ were measured three times on a computerised spirometer hooked to an X-Y recorder and the best trial recorded.

Respiratory muscle strength

Respiratory muscle strength was assessed by measuring the maximal inspiratory mouth pressure (PImax) and expiratory pressure (PEmax) at residual volume (RV) and total lung capacity (TLC), respectively, as previously described by Black and Hyatt. ${ }^{14}$ The value obtained from the best of at least three efforts was used.

\section{Respiratory muscle endurance}

To determine inspiratory muscle endurance, a device similar to that proposed by Nickerson and Keens ${ }^{15}$ was used. Subjects inspired through a two way Hans-Rudolph valve whose inspiratory port was connected to a chamber and plunger to which weights could be added externally. Inspiratory elastic work was then increased by the progressive addition of 25-100 g weights at two minute intervals as previously described by Martyn and coworkers ${ }^{16}$ until the subjects were exhausted and could no longer open the valve and inspire through it. The pressure achieved with the heaviest load (tolerated for at least 60 seconds) was defined as the peak pressure (PmPeak). The respiratory muscle endurance was defined as the ratio between the PmPeak and the PImax in absolute \%. The endurance after surgery was measured as the ratio between the new PmPeak and the new PImax so it actually measured the patient's new respiratory muscle endurance. Because the threshold device is independent of flow, the same pressure has to be generated by each patient in order to be able to inspire through it, and is independent of the pattern of breathing adopted by the patient.
To avoid motivation and learning effects on the results of the respiratory muscle performance tests, each patient was trained in performing the tests several times before entering the study until the results were reproducible for at least three trials.

\section{Lung volumes}

FRC was measured in a variable pressure constant volume body plethysmograph using a standard technique. ${ }^{17}$ TLC was obtained by adding inspiratory capacity (IC) to FRC, RV was obtained by subtracting FVC from the TLC, and ERV was obtained by subtracting RV from the FRC.

\section{DATA ANALYSIS}

Differences in variables before and after surgery were compared using paired $t$ tests. The level of significance was set at $\mathrm{p}<0.05$.

\section{Results}

The mean (SE) BMI was 41.5 (1.3) $\mathrm{kg} / \mathrm{m}^{2}$ before surgery and was significantly reduced to $31.7(1.1) \mathrm{kg} / \mathrm{m}^{2}$ six months after the operation (mean difference $9.8,95 \%$ CI 7.8 to 11.7 , $\mathrm{p}<0.0001)$ when the postoperative measurements were performed.

\section{Spirometric parameters}

The preoperative and postoperative parameters are shown in table 1 . The baseline FVC was reduced while the $\mathrm{FEV}_{1} / \mathrm{FVC}$ ratio was within the normal range. Postoperatively there was a significant increase in FVC while the $\mathrm{FEV}_{1}$ and the $\mathrm{FEV}_{1} / \mathrm{FVC}$ ratio were not significantly changed.

\section{Lung volumes}

Lung volume measurements (table 2) revealed that TLC, FRC, ERV, and RV were significantly reduced before surgery. Postoperatively there was a significant increase in TLC $(p<0.01)$, FRC $(p<0.05)$, ERV $(p<0.01)$, 


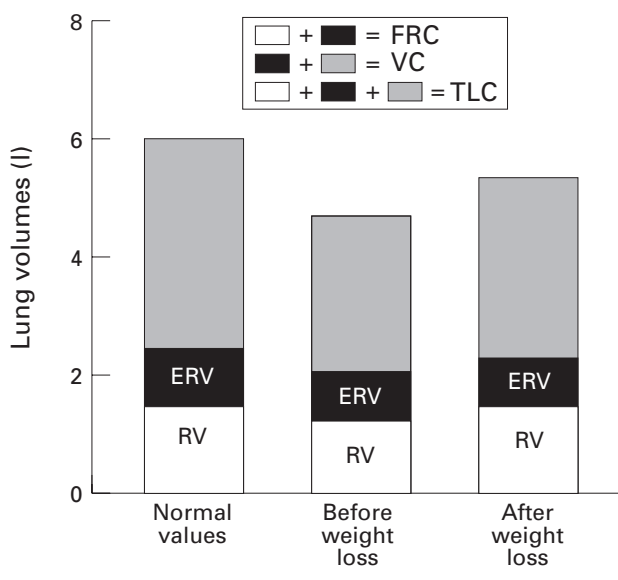

Figure 1 Mean lung volumes in healthy subjects and in obese subjects before and after significant weight loss. Total lung capacity (TLC), functional residual capacity (FRC), expiratory reserve volume (ERV), and residual volume $(R V)$ were significantly reduced before surgery and were significantly increased following weight loss.

and RV ( $\mathrm{p}<0.05)$, while there was no significant change in the RV/TLC ratio (fig 1 ).

\section{Respiratory muscle performance}

The inspiratory and expiratory muscle strength as assessed by the PImax and Pemax were slightly, although significantly, reduced $(\mathrm{p}<0.05)$ compared with predicted normal values, as suggested by Black and Hyatt, ${ }^{14}$ while the inspiratory muscle endurance, assessed by the PmPeak/PImax ratio, was even more markedly reduced $(p<0.001$; table 3$)$. Following weight loss there was a significant increase in respiratory muscle strength and endurance. The improvement in respiratory muscle performance correlated significantly with the weight loss following surgery and the strongest correlation was with the improvement in respiratory muscle endurance $\left(\mathrm{p}<0.001, R^{2}=\right.$ 0.71 ; fig 2).

\section{Discussion}

This study shows that the predominant abnormalities in respiratory function in obese patients are significant reductions in lung volumes and respiratory muscle endurance and less marked reductions in respiratory muscle strength. All parameters increased towards normal values after weight loss.

Respiratory function is determined by the interaction of the lungs, chest wall, and respiratory muscles. Obesity might therefore be expected to influence lung function through its effect on the chest wall and the respiratory muscles. Generally, the mechanical properties

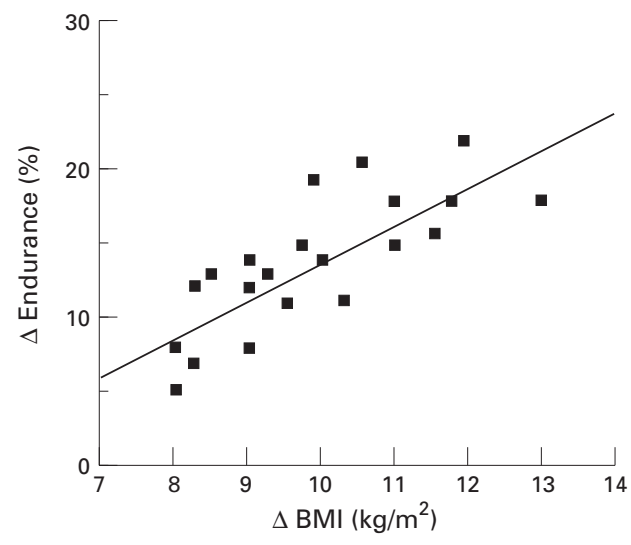

Figure 2 Correlation between increased respiratory muscle endurance and the loss in body mass index (BMI) following surgery $\left(p<0.001, R^{2}=0.71\right)$.

of the lungs are normal and the compliance of the chest wall is reduced. ${ }^{2}$ In addition, Cherniack and associates ${ }^{9}$ have shown inefficient respiratory muscles in obese individuals which may result from either reduced chest wall compliance or the lower lung volume at which ventilation takes place. PImax and Pemax were also found to be lower than predicted in obese individuals. ${ }^{13}$ Although respiratory muscle endurance was not measured in obese patients, the MVV, which is affected by the respiratory muscles, ${ }^{1819}$ has been found to be low ${ }^{16}$ or normal. ${ }^{820}$ Weight loss following either ileal bypass or gastroplasty for obesity has been found to increase VC, FRC, TLC, and ERV. ${ }^{11} 12$

Wadström and coworkers ${ }^{13}$ reported that, despite a weight loss of $18 \%$ and increased lung volumes, their obese patients showed no significant change in respiratory muscle strength. However, it should be noted that the $18 \%$ weight loss was achieved after a mean of 78 days and other investigators ${ }^{21}$ have reported a transitory decrease in muscle strength for several weeks after weight reduction. Wadström and coworkers probably performed their measurements immediately after this period, while our patients were studied six months after surgery and after having lost significantly more weight (mean $23.6 \%$ ).

There is still some uncertainty with regard to the factors responsible for the improved respiratory endurance. The reduced chest wall compliance may partially increase following weight reduction. This, and the increase in lung volumes associated with weight loss, should lead to a reduction in respiratory muscle inefficiency in obese patients. Respiratory muscles become fatigued when an imbalance occurs between energy supply and energy de-

Table 3 Mean (SE) respiratory muscle performance in obese subjects

\begin{tabular}{lccl}
\hline & Before surgery & After surgery & Mean difference (95\% CI) \\
\hline PImax $\left(\mathrm{cm} \mathrm{H}_{2} \mathrm{O}\right)$ & $92(4.4)$ & $113(4.6)^{* *}$ & $21(12.2$ to 31.6$)$ \\
PEmax (cm H2 & $144(5.9)$ & $69(4.3)^{* *}$ & $22(12.9$ to 32.0$)$ \\
PmPeak/PImax $(\%)$ & $56(1.4)$ & $13(9.7$ to 16.3$)$ \\
\hline
\end{tabular}

PImax, Pemax = maximum inspiratory and expiratory pressures; PmPeak = peak pressure

** Statistically significant. 
mand. Energy demand decreases with improved chest wall compliance and increased lung volume, as occurs when patients lose weight, and fatigue of the respiratory muscles is delayed and improved endurance or MVV test should occur. On the other hand, energy supply, which may be increased by treating hypoxaemia, is not relevant in our group of patients as none was hypoxic before surgery.

Lung volumes improved following weight loss. Increased lung volumes would explain an improvement in expiratory muscle function but not in inspiratory muscle function. An alternative possibility for the improvement in respiratory muscle performance is a change in the characteristics of the respiratory muscles following weight reduction. It has been shown previously ${ }^{21}$ that weight reduction is associated with an increase in isokinetic muscle endurance, probably due to an increase in glycogen synthase activity. However, this increased activity has not been shown in the respiratory muscles.

In summary, significant loss of body weight following gastroplasty in obese individuals caused significant increases in lung volumes and respiratory muscle performance. Weight loss, as a dependent variable, was best correlated with the improvement in respiratory muscle endurance.

1 Bedell GN, Wilson WR, Seebohm PM. Pulmonary function in obese person. $\mathcal{f}$ Clin Invest 1958;37:1049-60.

2 Naimark A, Cherniack RM. Compliance of the respiratory system and its components in health and obesity. $\mathcal{F} A p p l$ Physiol 1960;15:377-82.

3 Barrera F, Reidenberg MM, Winters WL. Pulmonary function in the obese patient. Am F Med Sci 1967;254:785-96.

4 Luce JM. Respiratory complications of obesity. Chest 1980; 78:626-31.
5 Alexander JK, Amad KH, Cole WW. Observations on some clinical features of extreme obesity, with particular reference to cardiorespiratory effects. Am f Med 1962;32: 512-24.

6 Cullen JH, Formel PF. The respiratory defects in extreme obesity. Am f Med 1962;32:525-31.

7 Ray CS, Sue DY, Bray G, Hansen JE, Wasserman K. Effects of obesity on respiratory function. Am Rev Respir Dis 1983; 128:501-6.

8 Dillard TA, Huatiuk OW, McCumber TR. Maximum voluntary ventilation: spirometric determinants in chronic obstructive pulmonary disease patients and normal subobstructive pulmonary disease patients and
jects. Am Rev Respir Dis 1993;147:870-5.

9 Cherniack RM, Guenter CA. The efficiency of the respiratory muscles in obesity. Can f Biochem Physiol 1961; 39:1211-22.

10 Sahebjami H, Gartside PS. Pulmonary function in obese subjects with a normal FEV /FVC ratio. Chest 1996;110: 1425-9.

11 Santesson J, Nordenstrom J. Pulmonary function in extreme obesity. Influence of weight loss after intestinal shun operation. Acta Chir Scand (Suppl) 1978;482:36-40.

12 Thomas PS, Owen CERT, Hulands G, Milledge JS. Respiratory function in morbidly obese before and after weight loss. Thorax 1989;44:382-6.

13 Wadström C, Muller-Suur R, Backman L. Influence of excessive weight loss on respiratory function. Eur $\mathcal{F}$ Surg 1991; 157:341-6.

14 Black LF, Hyatt RE. Maximal respiratory pressures: norma values and relationship to age and sex. Am Rev Respir Dis 1969;99:696-702.

15 Nickerson BG, Keens TG. Measuring ventilatory muscle endurance in humans as sustainable inspiratory pressure. f Appl Physiol 1982;52:768-72.

16 Martyn JB, Moreno RH, Pare PD, Pardy RL. Measurement of inspiratory muscle performance with incremental of inspiratory muscle performance with incrementa

17 DuBois AB, Botelho SY, Bedell GN, Marshall R, Comroe JH Jr. A rapid method for measuring thoracic gas volume: a comparison with a nitrogen washout method for measuring functional residual capacity in normal subjects. 7 Clin functional residual capa

18 Aldrich TK, Arora NS, Rochester DF. The influence of airway obstruction and respiratory muscle strength on maximal voluntary ventilation in lung disease. Am Rev Respir Dis 1982;126:195-9.

19 Lavietes MH, Clifford E, Silverstein D. Relationship of static respiratory muscle subjects. Respiration 1979;38 $121-6$

20 Gilbert R, Sipple JH, Auchincloss JH. Respiratory control and work of breathing in obese subjects. F Appl Physio 1961;16:21-6.

21 Krotkiewsky M, Grimby G, Holm G, Szczepanik J. Increased muscle dynamic endurance associated with weight reduction on a very-low-calorie diet. Am f Clin Nutr 1990; 51:321-30. 


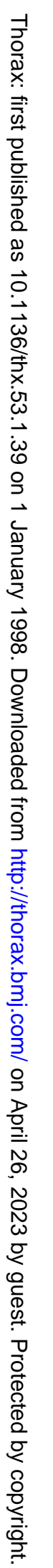

